\title{
A prescripção dos honorarios medicos (*)
}

1) - Manda a prudencia que o medico não retarde por muito tempo a liquidação dos honorarios.

A demora, quando excessiva, impressiona mal os tribunaes, que da inercia prolongada do facultativo tiram pos vezes argumento contra a procedencia do pedido ( $\mathrm{r}$ ).

Além disso, como todos os direitos de credito, o do medico está sujeito a desapparecer pela prescripção extinctiva.

Duas são as principaes questðes que surgem em materia de prescrip̧̧ão: a do prazo e a do ponto de partida.

2) - Não existe no corpo de nossa legislação preceito algum, que determine prazo especial para a prescripção dos honorarios medicos.

Em falta de norma peculiar á especie, applica-se a disposição geral, que é na hypothese a Ord. 4.79 pr. Por essa Ord. é de trinta annos o prazo ordinario da prescripção dos direitos pessoaes. Está, portanto, subordinada á prescripção trintennaria a acção

$\left(^{*}\right)$ O artigo que se vae ler constitue o capitulo IV de um livro em elaboração sobre os honorarios medicos.

(1) Trib. de Justiça de S. Paulo, 27 Jan. 1906 (S. Paulo Judiciario, 10.68); Rel. do Rio, 6 Set 1898, confirmado nesta parte pelo de 20 Junho 1896 (Rev. de Jurispr 11. 55). - Atravez de sua redacção tortuosa, o acc. do Trib de Just. de S. Paulo, 3 Novembro 1906, confirmado pelo de 22 Maio 1907 (S. P. Jud. 14. 133), deixa perceber que se filia á these contraria. 
que tem o medico para cobrar o que lhe fôr devido a titulo de honorarios (2).

$\mathrm{Ha}$, todavia, quem pretenda que o direito creditorio do medico seja prescriptivel em tres mezes. Em abono de tal opinião, ora invocam a legislação dos povos cultos como subsidiaria da nossa (3), ora procuram estender por analogia aos honorarios medicos a disposição que regula a prescripção dos salarios e custas judiciaes (4). Outros, inspirando-se no art. 2272 do Cod. Civ. Francez (hoje revogado), opinam péla prescripção de um anno (5).

Semelhantes opiniões são de todo em todo improcedentes.

Porque, antes de tudo, a funç̧ão tanto do direito estrangeiro como da analogia é simplesmente suppletiva: não se manifesta senão quando a lei é deficiente, lacunosa, omissa. Uma vez que a Ord. 479 pr. determina o prazo para a prescripção da generalidade das acções pessoaes e nesse numero se inclue indisputavelmente a acção de cobrança que compete ao facultativo, é contrasenso dizer-se que ha neste ponto uma lacuna da lei e pretender-se preenchel-a.

(2) Paulo de Lacerda, Gaz Jurid. de S. Paulo, 46.25; Estevam Pinto, Revista Forense, 8.119; F. Sandin, Direito, 83.228; Rel. de Ouro Preto, 7 Dezembro 1878 (Dir. 18.286); Rel. de Porto Alegre, 11 Junho e 17 Setembro 1880 (Dir. 26.170); 2.a Cam. da Côrte App. do Rio, 27 Dezembro 1907 (Dir. 107.276).

(3) Almeida e Oliveira, Prescripção, p. 419 e nota 122. Cita erradamente o Cod Napoleão, sem dizer, aliás, o artigo que possa apadrinhar-lhe o parecer. 26.170 .

(4 Opinião de que dão noticia Paulo de Lacerda, 1. c., e Dir.

(5) Cam. Civ. do Trib. Civ. e Crim. do Rio, 30 Abril 1900 (Dir. 82.197): Cons. que as dividas de honorarios medicos prescrevem em 1 anno (cod. civ. fr., art. 2272 ; CoElHo DA Rocta, $\$ 465$, nota; Corrêa Telles, Dig. Port., vol. 1, art. 1323) „.. As citaçōes não podiam ser mais infelizes. Ao tempo do accordam, o art. 2272 do cod. civ. fr. já estava alterado pela lei de 30 Novembro 1892; e tanto Coelho DA Rocha como CorRêa Telues se limitam a formular um voto de jure constituendo: edesideratur», diz o ultimo escriptor. 
Além disso, nenhuma legislação moderna consigna - prazo curtissimo de tres mezes para a prescripção extinctiva da divida de honorarios (6). Quanto ao prazo de um anno, o codigo português é o unico a acceital-o.

$E$, finalmente, seria desacerto indefensavel applicar-se ao caso, por analogia, qualquer das disposições que estabelecem prescripções especiaes para determinadas classes de direitos. As prescrip̧ões especiaes constituem excep̧̧ões, e exceptiones sunt strictissimøe interpretationis (7).

2. ${ }^{\text {bis }}$-Não queremos dizer com isso que a legislação actual seja extreme de censura. $\mathrm{O}$ caso em debate é precisamente um dos que reclamam o cerceamento do prazo ordinario e a adopção da prescripção brevi temporis. Disse muito bem, no senado francês, um medico, o dr. Cornil, ao discutir-se o projecto que se transformou na lei de I892: trata-se de um credito, que ordinariamente se compõe de verbas mul tiplas, de que nem sempre se guarda memoria precisa; trata-se de uma divida cujo pagamento é muitas vezes feito em confiança, sem quitação ou recibo. Combatendo a disposição do projecto, que elevava a cinco annos o prazo, Cornil sensatamente ponderava: "Se o lapso de um anno é demasiado breve, o de cinco annos é demasiado longo. Em primeiro logar, o medico, que não apresenta a sua conta senão ao fim de cinco anhos, dá mostras de uma negligencia que não merece animação. Em segundo logar, decorrido esse tempo,

(6) Almeida e Ouiveira, 1. c., appellou para o cod. civ. fr. Lapso palpavel: ao tempo em que escreveu Almeida e Oliverra, a disposição que na França regulava o assumpto era o art. 2272 do cod., e esse fixava em 1 anno. e não em 3 mezes, o prazo para a prescripção de "l'action des médecins. chirurgiens et apothicaires». Hoje a disposição vigente é a lei de 30 Novembro 1892, art. 11: - L'action des médecins, chirurgiens, chirurgiens-dentistes, sagesfemmes et pharmaciens, pour leurs visites, opérations et médicaments, se prescrivent par deux ans». Veja-se o historico da reforma em Brodardes, Exercice de la médecine, 67 e s.

(7) Baudry-Lacantinerie, Précis, 3.984. 
só com muita difficuldade poderá o cliente verificar a exactidão da conta: será victima constante de erros inverificaveis. $E$, por ultimo, porque deixarmos que os honorarios se accumulem durante annos e annos, arriscando-nos a permittir que o seu quantum se torne esmagador para o cliente?" (8).

Eis o motivo por que todas as legislações contemporaneas despem de acção o direito creditorio do medico ao fim de breve lapso de tempo (9).

No mesmo sentido se têm manifestado os varios projectos do codigo civil brasileiro (Io), satisfazendo dest'arte á velha aspiração dos nossos juristas (I I).

(8) Brouarder, p. 73.-Fosse mais curta, por direito patrio, a prescripção dos honorarios, e certamente nâo veriamos o triste espectaculo que alguns medicos nos offerecem, aguardando, muito de industria, durante lustros e lustros, a morte do : cliente, para atirar-se então ao assalto longamente premeditado. Este espera nove annos para cobrar-se de 15:000\$000; aquelle-vinte e tres, para reclamar 345:000\$000... Tomam elles á letra as palavras de VIEIRA: - as quaresmas dos enfermos são as paschoas dos medicos...»

(9) Um anno, pelo cod. civ. português, art. 359, n. ¿. Dois annos, pelo cit. lei francêsa de 1892, art. 11 ; pelos codigos allemão, art. 196, n. 14,-argentino, art. 4032,-uruguayo, art. 1197. Tres annos, pelos cods. italiano, art. 2521,--peruano e veneruelano, apud R. De ta Grasserre, Cod. civ. péruv.116, e Cod. civ. de Vénézuela, 224.

(10) Proj. Fentcio, art. 1359: "Prescrevem pelo lapso de um anno... $2^{0}$-as retribuições de medicos e cirurgiões pelas suas visitas e operações \$.-Proj. Coklho Rodrigues, art. 255: ‘ Prescreve em seis mezes a acção... $\S 60^{\circ}-$ dos medicos e cirurgiôes ou pharmaceuticos por suas visitas ou operações ou medicamentos fornecidos sob prescripção de facultativo. Art. 260: Os medicos, cirurgiōes e pharmaceuticos devem liquidar e cobrar ou fazer reduzir o documento escripto pelo devedor as suas contas dentro do prazo do art. 255, sob pena de serem consideradas pagas as do semestre anterior, ainda que seus serviços ou fornecimentos tenham continuado"-Poj. Bevilaqua primitivo, art. 203: «Prescreve em seis mezes a acção .. 5.0 dos medicos ou cirurgióes ou pharmaceuticos por suas visitas, operaçōes e medicamentos fornecidos mediante prescripção medica ". O proj. Bevilaqua revisto elevou o prazo a um anno (art. 212, 5. ) $^{-}$No proj. approvado pela Camara, o assumpto é regulado pelo art. 182 : «Prescreve... $\$ 6.0^{\circ} \mathrm{em}$ um anno... X. a acção dos medicos, cirurgiões ou pharmaceuticos, por suas visitas, operações ou medicamentos, correndo o prazo da data do ultimo serviço prestado». Não encontrei vestigios da apresentação e votação da emenda, que se converteu na ultima parte do artigo.

(11) Lobão, Notas a Mello, 3 t. 4 \& n. 3: Corrêa Telles, Dig. Port. 1, n. 1323: Coexho DE RochA, nota ao $\S 465$. 
Com rigor excessivo, o projecto Bevilaqua marcava o prazo angustissimo de seis mezes. A commissão revisora dilatou o praso a um anno e a modificação foi acceita pela Camara. Dado o costume geral de serem apresentadas annualmente as contas medicas, o lapso justo e razoavel seria o de dois annos, e não o de um, conforme está no projecto (I 2). Conviria igualmente que á mesma prescripção ficassem expressamente sujeitos os honorarios de dentistas e parteiras.

3)-Qual o ponto de partida da prescripção liberatoria?

A prescripção nasce no momento em que o titular do direito pode exigir o pagamento e deixa de fazel-o (I 3 ). Mas a difficuldade está precisamente na determinação do momento em que se torna exigivel a divida de honorarios medicos.

Nenhuma duvida se nos depara no caso de tratamento a forfait: o' vencimento da obrigação coincide com a terminação da molestia pela cura ou pela morte, e é a partir desse instante que se conta o prazo da prescripção (I 4 ).

Não ha tambem vacillação possivel quando o trabalho consta de uma só visita, consulta, operação ou conferencia; e da mesma fórma quando se trata de visitas avulsas, espaçadas, intermittentes e não de uma assistencia ininterrupta e continua. $O$ prazo corre

(12) No substitutivo apresentado pelos srs. Torres Neto e Toumntino mandava-se prescrever "no lapso de dois annos... $2 .{ }^{\circ}$ a retribuicão dos medicos e cirurgiōes por suas visitas ou operações». (Trabalhos do cod civil. 4.208). O substitutivo foi votado e rejeitado em globo (Trab. 5. 123).

(13) Cuovis, Theoria geral do direito civil, 390. Ord. 4.79 pr.

(14) Guerrier e Rotureau, Jurispr: Méd. 264. 
entåo do dia em que tem logar o serviço e cada visita ou consulta tem a sua prescripção especial (I 5 ).

3. ${ }^{b i s}$ ) - Supponhamos, porém, -e essa é precisamente a hypothese mais commum,-supponhamos que o medico tenha feito ao cliente varias visitas successivas, reclamadas pelo tratamento de uma determinada molestia. Quem diz tratamento diz seriação de visitas, direcção seguida, continuidade de cuidados.

Como, em tal emergencia, deve ser contado o prazo: do dia de cada visita ou do dia da ultima, sómente? Por outras palavras: ha tantas prescripçôes quantas sejam as visitas ou a prescripção é uma só para todo 0 credito?

Uma pequena minoria acceita a primeira dessas duas soluções (I6). Para os autores em questão, cada visita prescreve separadamente, porque, apezar de todas serem feitas no decurso do mesmo tratamento, cada uma dellas representa um credito distincto. A praxe de calcular os honorarios a tanto por visita está a indicar que um novo credito se constitue todas as vezes que o facultativo presta os seus cuidados ao enfermo; e tanto isso é verdade que nada o inhibe de cobrar os seus honorarios á proporção que vae prestando os serviços.

Alguns escriptores entendem igualmente que os honorarios se decompoem em tantos creditos independentes quantas sejam as visitas ou operações. Mas accrescentam que em virtude de uma convençâo tacita entre as partes, esses differentes creditos não se fazem exigiveis senão depois de decorrido um certo prazo fixado pelos usos e costumes locaes. Assim, a

(15) Cod. civ. port, 264, art. $359 \S 10^{0}$ : «... e a prescripção das visitas avulsas (corre) desde o dia em que cada uma é feita .

(16) Aubry e Rad, 8.442, $\$ 774$; Vazeille, cit. por Dubrac, $J u$ rispr. méd., n. 294. 
prescripção correrá do termo do tratamento, sempre que tal seja o costume da terra (I 7). Assim tambem, nos logares em que habitualmente as contas são apresentadas a $\mathrm{I}^{\circ}$ de Janeiro, começará nesse dia a prescripção das visitas e mais serviços effectuados no transcurso do anno anterior (18).

Outros distinguem as molestias chronicas das molestias agudas. Nestas a prescripção é uma só para a totalidade dos honorarios: o prazo se conta do dia em que se ultíma o tratamento. Naquellas ha tantas prescripções quantos forem os serviços: cada visita está sujeita a uma prescripção distincta (19).

De accordo, emfim, com a opinião dominante na jurisprudencia e na doutrina é da ultima visita ou do ultimo trabalho que decorre o prazo da prescripsão extinctiva, qualquer que seja a natureza da molestia (20). Prestigiada pela maioria dos julgados e autores estrangeiros, foi essa a opinião que prevaleceu no projecto do codigo civil em discussão no Congresso (2 I). E com n. 1970

(17) Marcadé, Comm. ao art. 2274 ; Mourlon, Rep. écr., t. 3,

(18) Valentrin, Le médecin devant la loi, n. 108, p. 102. Neste sentido vejam-se dois julgados de tribunaes belgas em Strex, 94.4.32 e 92.4 .24 3 , ก. 1970

(19) Duranton, 21, n.413, Troplong, Prescr. n. 959; Modrlon,

(20) Pothier, Oblig. n. 715 ; Planiol, Dr. civ. II, n. 650, B. Lacantinerie e Tissier, Prescription, n. 733; Dubrac, n. 295; Carette, Jurisprud argent., h. v., n. 107; FLOQUet, Cod. des honor., 379; Perread, Jurispr. méd., 233; Salats, Honor. méd., 127; Guerrier e Rotureau, 260 ; Pabon, Exerc. de la méd. n. 185.-O art. $359 \$ 1 .^{\circ}$ do cod civ. port. é expresso: « A prescripção das visitas dos medicos e cirurgiōes e relativas á mesma pessoas e molestia, corre desde a data da ultima visita .

(21) Nem o proj. primitivo, nem o revisto fixavam o ponto de partida. Ao entrar em discussão essa parte do projecto no seio de commissão especial, os srs. Torres Nero e Tolentino offereceram a seguinte emenda, inspirada manifestamente no cod. civ. port. : \& 1. A prescripção das visitas dos medicos e cirurgiōes, seguidas e relativas á mesma pessoa e molestia, corre desde o dia da ultima visita; e a das visitas avulsas. desde o dia em que cada uma é feita.. (Trab. 5.123). 
razão. Os honorarios relativos á mesma pessoa e molestia representam um credito unico, que sómente se intégra no momento em que cessam as relaçбes entre o medico e o enfermo. A menos que se trate de consultas e visitas avulsas, o contracto que vincula o fa. cultativo ao cliente apresenta a mais estreita analogia com a locatio operis: o seu objecto é o tratamento de uma determinada molestia. Ninguem dirá que, ao cabo de cada visita, o facultativo tenha concluido a sua missão ou satisfeito de prestação que lhe incumbe. Porque em regra o facultativo não pode realisar a tarefa num só dia, o clinico visita repetidamente o enfermo, acompanhando a evolução do morbo; e, assim, cada visita não representa a execução de um novo serviço, mas a prosecução de um trabalho já iniciado. As visitas, por maior que seja o seu numero, devem ser consideradas como elementos de um acto complexo em suas phases diversas.

$\mathrm{O}$ costume de serem calculados os honorarios a tanto por visita não collide com o principio da unidade do credito. No contracto de transporte, por exemplo, as tarifas são pactuadas á razão de tanto por kilometro; nem por isso cada kilometro percorrido faz surgir um credito novo em beneficio do transportador (22).

Da mesma fórma, não procede o argumento de ser licito ao medico exigir o pagamento dos honorarios á proporção que vae executando o serviço. Em regra, a cobrança immediata é reprovada pelo costume geral, contraria aos estylos da profissão, considerada como offensiva á dignidade do cliente (23). Só em casos

(22) Salats, p. 127.

(23) Na Inglaterra a visita medica é paga geralmente á vista. Trata-se, v. g, de um clinico que exige uma libra por visita. $E$ chamado a ver o doente. Finda a visita, o cliente paga-lhe duas libras. Volta no dia seguinte recebe mais uma libra. Ao terceiro dia faz outra visita e nada recebe: não volta mais. A ultima visita foi 
muito epeciaes é possivel ao medico utilisar-se dessa, faculdade. Quasi sempre o pagamento se faz depois de ultimado o tratamento, quando a molestia é aguda, ou depois de conjurada a crise, quando a molestia é chronica. Seja, porém, como fôr, a circumstancia allegada não é incompativel com a these da unidade da divida. Facto identico se verifica emquanto aos salarios e custas judiciaes. Os salarios marcados no regimenta podem ser exigidos, logo após á conclusão dos actos respectivos (24), o que nåo impede que o direito de cobral-os sómente prescreva decorridos tres mezes sobre a data da sentença final (25).

Entendemos assim que a prescripção dos honorarios têm por inicio o dia em que cessa o tratamento ou por motivo de terminação da molestia ou por motivo de exoneração do facultativo.

Claro está que os serviços prestados por occasião de uma nova molestia não impedem o curso da prescripção dos honorarios relativos a uma molestia anterior (26): corre do fim de cada molestia uma prescripção differente.

3. ${ }^{\text {ter }}$ - $\mathrm{O}$ principio que vimos de acceitar deve . soffrer em certos casos um temperamento. Por vezes a molestia apresenta phases distinctas e nitidas, sepa-

retribuida 'ao mesmo tempo que a primeira, pela qual o cliente pagou o dobro da tarifa habitual (Brovardel, p. 434). O systema é essencialmente pratico. Elimina todo e qualquer debate sobre quantidade e o preço do trabalho; salvaguarda os interesses do enfermo e o direito do medico; e permitte ao cliente dispensar os serviços do facultativo por uma fórma discreta e delicada.

(24) Decr. fed. n. 3084, de 5 Novembro 1898, parte $1 \mathrm{a}$, art. 253.-Decr. est. de S. Paulo, n. 178, de 6 Junho 1893, art. 172.

(25) Ord. $1.79 .18 ; 1.84 .30 ; 1.92 .18$. Decr. fed.n. 3084, parte 3.a, art. 841, n. 3 .

(26) Pothier, n. 715; Floquet, p. 380; Prunrer, Cond. jurid. des méd. 67.-Carette, l. c., n. 112: cLa prescripción de los honorarios médicos empieza desde la fecha en que cesa la existencia temporal, aun cuando por otra enfermidad se requieran nuevamente os servicios del mismo facultativo . 
radas por longos intervallos, com interrupção da assistencia medica. Sirvam de exemplo certas molestias chronicas que não demandam cuidados assiduos do clinico senão durante as crises. Além desse, podemos figurar outros casos de tratamento discontinuo e intermittente, em que a meio da molestia cessam de todo as relações entre o facultativo e o cliente para só recomeçarem mais tarde. E' justo que, em casos taes, se discriminem para o effeito da prescripção os differentes periodos em que tenha havido assistencia. Ad. mitte-se então a existencia de tantos creditos quantas sejam as series de visitas ou trabalhos profissionaes: do dia da ultima visita ou trabalho de cada periodo corre uma prescrịpção especial para os honorarios vencidos nesse tracto de tempo. (27)

Dr. Alcantara Machado.

(27) Perreau. 234; Gugrrier e Rotureau, 262; Salats, 1.28; Dubrac, n. 295. Caretre, 1. c., n. 107 : Opuesta la excepción de prescripción. aun cuando se trate de una sola y misma enfermedad, no puede pretenderse que los servicios han sido continuos cuando lo han sido en tres periodos, con intervalo de un año y más, cada uno». 